\title{
Study of Interaction between Febuxostat and Bovine Serum Albumin by Fluorescence Spectroscopy
}

Sikder Nahidul Islam Rabbi ${ }^{1}$, Md. Zamil Sultan ${ }^{2}$, Md. Didaruzzaman Sohel ${ }^{1}$ and Md. Zakir Sultan ${ }^{3 *}$

${ }^{1}$ Department of Pharmacy, State University of Bangladesh, Dhanmondi, Dhaka, Bangladesh

${ }^{2}$ Department of Electrical and Electronic Engineering, Hajee Mohammad Danesh Science and Technology University (HSTU), Dinajpur, Bangladesh

${ }^{3}$ Centre for Advanced Research in Sciences, University of Dhaka, Dhaka, Bangladesh

\begin{abstract}
The interaction of an anti-gout drug, febuxostat was studied with bovine serum albumin (BSA) applying fluorescence quenching method for the first time. Interaction parameter and magnitude of the force indicated for both, dynamic and static quenching in between febuxostat and BSA protein. Thermodynamic studies indicated for both hydrogen and hydrophobic interactions, observed at $280 \mathrm{~nm}$ and only hydrophobic at $293 \mathrm{~nm}$ excitation wavelength. Negative $\Delta \mathrm{H}_{\mathrm{o}}$ and positive $\Delta \mathrm{S}$, indicated for distinctive characteristics for the existence of both, hydrogen and hydrophobic binding throughout the interactions. The binding constant $\mathrm{K}_{\mathrm{b}}$ at $\lambda_{\mathrm{ex}}=280 \mathrm{~nm}$ was 3.467 $\times 10^{3} \mu \mathrm{M}^{-1}$ and $4.943 \times 10^{3} \mu \mathrm{M}^{-1}$ at 298 and $308 \mathrm{~K}$ temperature whereas, $5.54 \times 10^{3} \mu^{-1}$ and $4.44 \times 10^{3} \mu \mathrm{M}^{-1}$ was noted during excitation at $\lambda_{e x}=293 \mathrm{~nm}$ wavelength. The $\mathrm{K}_{\mathrm{b}}$ values in different temperatures assumed that the stability of binding increased with the increase of temperature at $\lambda_{\mathrm{ex}}=280 \mathrm{~nm}$, but reverse effect was experienced at an excitation wavelength of $\lambda_{\mathrm{ex}}=293 \mathrm{~nm}$. The number of bound febuxostat molecules per BSA protein was found $\sim 1.5$ at both 298 and $308 \mathrm{~K}$.
\end{abstract}

Keywords: Febuxostat; Bovine serum albumin; Interaction; Fluorescence spectroscopy; Dynamic quenching; Static quenching

\section{Introduction}

Plasma protein consists of a greater proportion of human circulatory system, irrespective of physiological functions, they are also important for drug distribution, disposition via pharmacokinetics and pharmacodynamics property [1]. Research with enormous interest in the drug-protein interaction also revealed the importance and influence of this interaction in the process of absorption, metabolism and excretion of xenobiotic [2]. Serum albumin being an abundant protein plays a vital role in animal physiology in the transportation of many drugs and hormones [3,4]. Binding with this serum albumin is a key factor, for any agonist or xenobiotic to give therapeutic actions. The extent of binding between drug and protein normally depends on many factors, including nature of drugs, hydrophobicity, electrostatic charge and $\mathrm{pH}$ of the drug molecules, etc. Most of the cases, a reversible binding of the drug with different bio-active compound is observed, when they function as carriers [5]. Dose and dosing interval completely depend on binding of drugs with different protein in the body. Quantification of circulating protein is always having a great importance in biology and medicine to understand and minimize the unwanted side effect of drug [6]. Escalating apparent solubility of hydrophobic drugs with the modulation pattern of bindings also plays a vital role in the delivery of drugs into the cell. Such interactions raise the concern of drug stability and toxicity related issues in a biological system [7]. In human, $60 \%$ of the circulating plasma is consisted with serum albumin [8]. Being a larger volume, it serves a wide variety of functions for endogenous and exogenous agonist to accentuate their therapeutic action on different receptors and channels. Bovine serum albumin (BSA), serve as a cheap source in studying drug protein interaction. Being $76 \%$ sequence homology it is believed that the 3D structure of the BSA and HSA are almost similar in nature [9]. Different studies comparing HSA and BSA, revealed that homology [9]. Considering 3D structure of HSA, it is suggested that the principal regions of ligand binding to HSA are located in hydrophobic cavities in the sub domain IIA and IIIA consisted with sites I and II including a single tryptophan residue in sub domain IIA $[10,11]$.
Nature and the affinity of binding is always a great indicator to quantify the therapeutic dose for an effective dosage regimen towards better therapeutic outcome. Degrees of interactions of drug with surrounding protein depend on the chemical nature of the drug particles. This concern potentiates the importance and necessity of studying the interactions in between drug and serum albumin in molecular level.

Gout, an acute arthritis appears with an inflammation in response to the accumulation of crystals of monosodium urate in or around a joint $[12,13]$. Characterized by hyperuricemia (serum urate concentration [SUA] exceeding $6.8 \mathrm{mg} / \mathrm{dL}$, the limit of urate solubility) and acute and chronic consequences of monosodium urate crystal deposition [14]. Renal calculi including prolong crystal disposition result in Renal damage may also occur and believe a prime cause of urinary tract stones composed of uric acid crystal [12]. Long term prophylaxis, is indicated for patients with recurrent gout attaches [14,15]. Prolong management of chronic gout with ULT focuses on achieving and maintaining sUA in a sub-saturating range $(<6.0 \mathrm{mg} / \mathrm{dL})$ with the objective of dissolving monosodium urate crystals and declining the body pool of uric acid $[16,17]$.

Febuxostat INN, a selective non-purine analog XO inhibitor [18] extensively prescribed for the treatment of chronic hyperuricemia in the patient's related to gout [19]. Data from 3 comparative blinded, randomized controlled trials (RCTs) have demonstrated the superior

*Corresponding author: Md. Zakir Sultan, Centre for Advanced Research in Sciences, University of Dhaka, Dhaka 1000, Bangladesh, Tel: +880 29661920 59, Extn 4722; Fax: +880 2966 7222; E-mail: zakir.sultan@du.ac.bd

Received July 12, 2015; Accepted September 22, 2015; Published September 25, 2015

Citation: Rabbi SNI, Sultan MdZ, Sohel MdD, Sultan MdZ (2015) Study of Interaction between Febuxostat and Bovine Serum Albumin by Fluorescence Spectroscopy. J Bioanal Biomed 7: 164-170. doi:10.4172/1948-593X.1000138

Copyright: (c) 2015 Rabbi SNI, et al. This is an open-access article distributed under the terms of the Creative Commons Attribution License, which permits unrestricted use, distribution, and reproduction in any medium, provided the original author and source are credited. 
efficacy of febuxostat $80 \mathrm{mg}$ daily compared with both the commonly prescribed doses of allopurinol $(300 \mathrm{mg}$ ) and placebo [20,21]. In addition, both approved doses of $80 \mathrm{mg}$ and $40 \mathrm{mg}$ of febuxostat are significantly more efficient than allopurinol $(\mathrm{p}<0.001$ and $\mathrm{p}=0.012$, respectively) in achieving the therapeutic target of sUA (Serum uric acid) in subjects with mild-to-moderate renal impairment [22]. In this paper, we tried to illustrate about the study of the interactions of febuxostat with bovine serum albumin (BSA) applying different supportive data including binding parameter, temperature variation and nature of binding. Binding constant at temperature differential also studied to elucidate the dependence of temperature on binding force actuations.

\section{Materials and Methods}

\section{Chemicals and reagents}

All reagents used in this study were of analytical standard; moreover double distilled water was used throughout the study. BSA was obtained from sigma chemical Co., USA and used devoid of further purification process. BSA solution $\left(2 \times 10^{-5} \mathrm{M}\right)$ was prepared in $0.1 \mathrm{M}$ phosphate buffer ( $\mathrm{pH} 7.40)$ and kept in $4^{\circ} \mathrm{C}$. Febuxostat standard was (potency: $>99.95 \%$ ) obtained from Incepta pharmaceutical Ltd., Bangladesh. Stock solution $\left(1.0 \times 10^{-3} \mathrm{M}\right)$ was prepared in $\mathrm{pH} 7.40$ buffer. Due to lack of complete solubility, febuxostat was first dissolved in DMSO and volume was adjusted by phosphate buffer $\mathrm{pH}$ 7.40. Buffer ( $\mathrm{pH}$ 7.40) solution was equipped with the mixture of $\mathrm{Na}_{2} \mathrm{HPO}_{4}(20 \mathrm{mM})$ and $\mathrm{NaH}_{2} \mathrm{PO}_{4}(30 \mathrm{mM})$. All of the $\mathrm{pH}$ measurement was performed by Hanna HI $2210 \mathrm{pH}$ meter, USA (Figure 1).

\section{Apparatus}

Fluorescence emission spectra were recorded on a Hitachi FL-7000 (Tokyo, Japan) fluorescence spectrometer equipped with $1 \mathrm{~cm}$ quartz cell. Observations were taken at two different temperatures $(298 \mathrm{~K}$ and $308 \mathrm{~K}$ ) using $5 / 5 \mathrm{~nm}$ slit widths. To aid in stabilizing of different temperatures, a thermostat bath Unitronic Orbital, Spain was used. The temperatures of the samples were maintained by recycling water throughout the experiment.

\section{Data measurement and analysis}

Statistical analysis and all others measurement were calculated by Microsoft Office Excel 2007 program. SD (Standard deviation) value was calculated statistically from three replicas run for each sample.

\section{Sample preparation and observation}

Stock solutions of $1000 \mu \mathrm{M}$ of febuxostat and BSA were prepared in phosphate buffer $\mathrm{pH}$ 7.40. Appropriate volumes of BSA to obtain 2 $\times 10^{-5} \mathrm{~mol}$. L- 1 or $20 \mu \mathrm{M}$ was prepared from the stock. The required

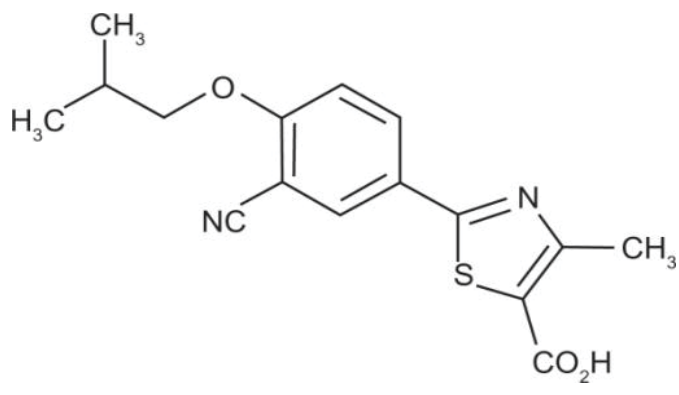

Figure 1: Structure of febuxostat. volume of febuxostat to get $20 \mu \mathrm{M}, 40 \mu \mathrm{M}, 60 \mu \mathrm{M}, 80 \mu \mathrm{M}, 100 \mu \mathrm{M}, 140$ $\mu \mathrm{M}, 180 \mu \mathrm{M}, 220 \mu \mathrm{M}, 280 \mu \mathrm{M}$ and $320 \mu \mathrm{M}$ concentrations respectively, were equipped from the stock solution. Fixed $20 \mu \mathrm{M}$ of BSA solution was mixed with each differential concentration of febuxostat in 1:1 (BSA: Febuxostat) volumetric ratio, in separated test tubes. Fluorescence spectra were recorded at two different temperatures $(298 \mathrm{~K}$ and 308 $\mathrm{K})$ in the range $250-600 \mathrm{~nm}$ upon excitation at 280 and $293 \mathrm{~nm}$ of BSA molecule considering location of tryptophan and tyrosine residue [23] in BSA protein. The mixed solution of BSA and febuxostat were mixed well by sonication later on incubated at $298 \mathrm{~K}$ and $308 \mathrm{~K}$ temperature for 30 minutes prior to the observation and spectral analysis. Phosphate buffer $\mathrm{pH} 7.40$ was served as blank to aid in pre-scan purpose.

\section{Results and Discussion}

Fluorescence quenching is the reduction of quantum yield of fluorescence from a fluorophore induced by a variety of molecular interaction with a quencher molecule [24,25]. An Increase in the concentration of quencher will mask the fluorophore, result in reduction of emitted fluorescence from the fluorophore molecules. In ease of targeting specific location regarding the binding pattern of BSA protein, we used different wavelength. Generally, the fluorescence of bovine serum albumins comes from tryptophan, tyrosine and phenylalanine residues. During data recording at an excitation wavelength at $280 \mathrm{~nm}$, fluorescence of albumin was coming from both tryptophan and tyrosine residues, whereas $293 \mathrm{~nm}$ wavelength excited tryptophan residues only [23].

Here, fluorescence emission of BSA was reported approximately at $340 \mathrm{~nm}$ region, where as febuxostat (quencher) also emitted fluorescence at $380 \mathrm{~nm}$. It happened as because drug itself also fluorescence active in nature. When the only BSA was excited, maximum emission intensity has been recorded at around $340 \mathrm{~nm}$ and these spectrums show a lower level of fluorescence emission at $380 \mathrm{~nm}$. So, emission at $380 \mathrm{~nm}$ began to increase with the increase of drug concentration, comparing fixed concentration $\left(\mathrm{CBSA}=2 \times 10^{-5} \mathrm{~mol} \mathrm{~L}^{-1}\right)$ of BSA.

\section{Analysis of fluorescence quenching of BSA by febuxostat}

The fluorescence measurement of interaction between the drugs or agonists with a protein provides some information regarding its binding mechanism, binding force, binding mode, binding constant including location or associations on a specific site on examined protein. Figure 2 illustrated the emission spectra of BSA in presence of various concentrations of quencher molecules (febuxostat). The characteristic fluorescence emission wavelength of BSA was around $340 \mathrm{~nm}$, indication of partial shielding of the tryptophan residues from aqueous solvent [15]. It was apparent that the fluorescence strength of BSA decreases consecutively with the increase in febuxostat concentration, implying that the binding of febuxostat to BSA occurred and the microenvironment around the fluorophore of BSA has been changed or blocked by available amount of drugs.

From Figure 2, the fluorescence emission wavelengths of BSA had obvious blue shifts after the addition of the drug molecules, indicated the location of tryptophan and tyrosine residue in BSA, in a more hydrophobic environment [10].

The fluorescence quenching data were analyzed by the well-known Stern-Volmer equation [25]: from equation 1

$$
\mathrm{F}_{\mathrm{o}} / \mathrm{F}=1+\mathrm{K}_{\mathrm{q}} \tau_{\mathrm{o}}[\mathrm{Q}]=1+\mathrm{K}_{\mathrm{sv}}[\mathrm{Q}]
$$

Here, where $\mathrm{F}_{\mathrm{o}}$ and $\mathrm{F}$ represent the fluorescence intensities in the absence and presence of the quencher molecule. [Q] is the concentration 
Citation: Rabbi SNI, Sultan MdZ, Sohel MdD, Sultan MdZ (2015) Study of Interaction between Febuxostat and Bovine Serum Albumin by Fluorescence Spectroscopy. J Bioanal Biomed 7: 164-170. doi:10.4172/1948-593X.1000138
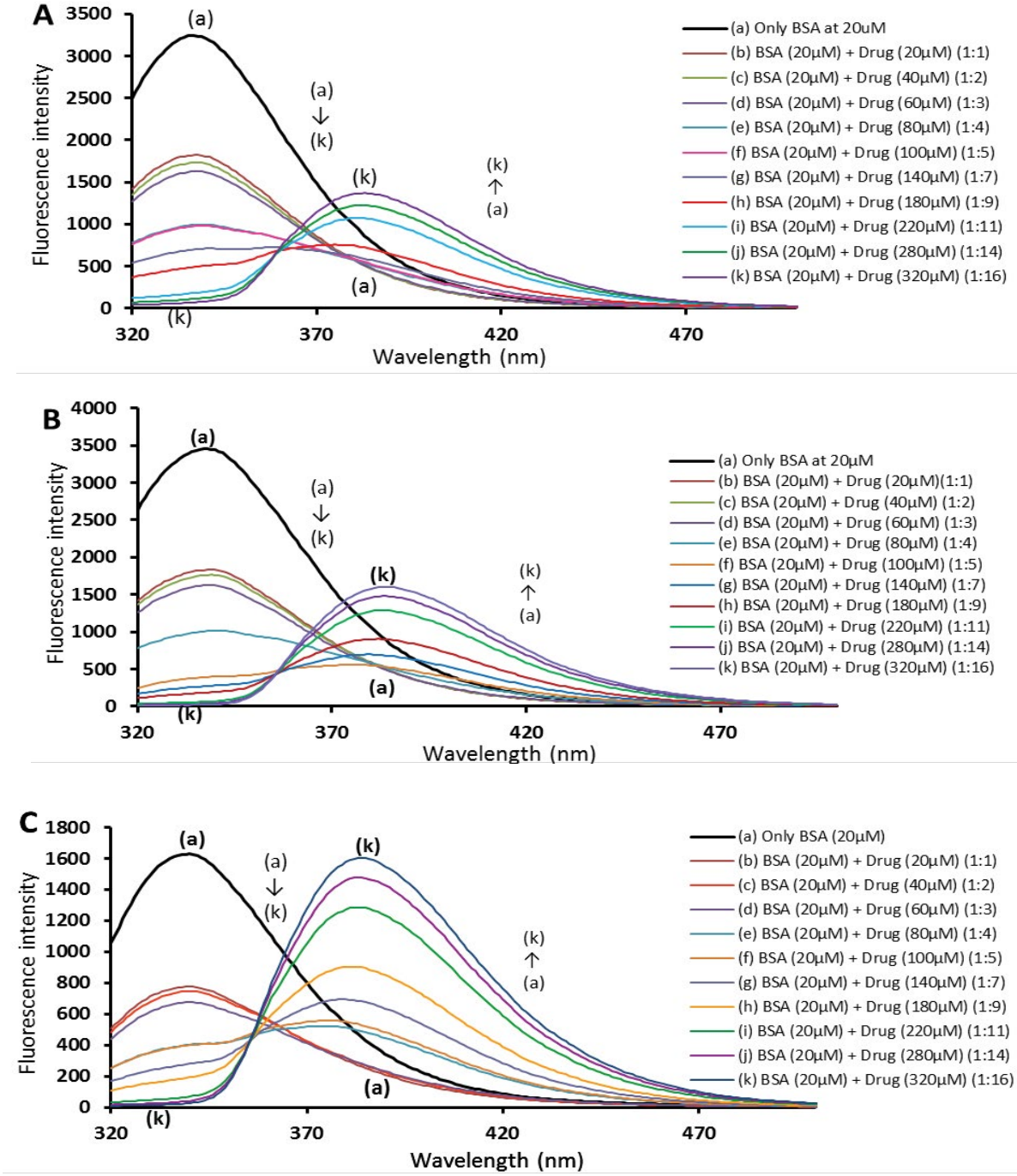

D

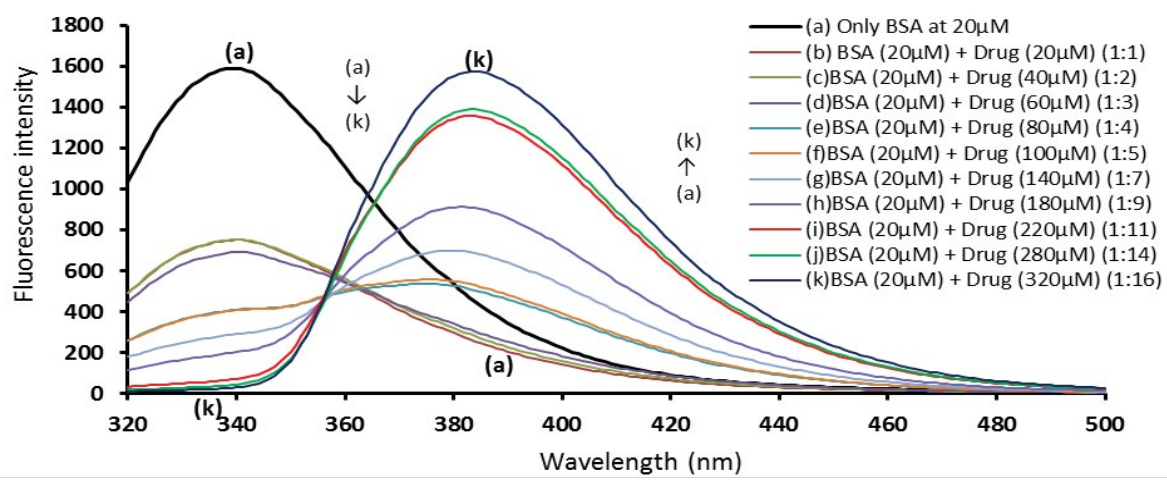

Figure 2: A. BSA fluorescence emission spectra in the presence of febuxostat, $\lambda_{\mathrm{ex}}=280 \mathrm{~nm}, \mathrm{CBSA}=2 \times 10^{5} \mathrm{~mol} \mathrm{~L}^{-1}$; molar ratio of drug to protein is $0,1,2,3,4,5,7$, $9,11,14,16 \mu \mathrm{M}$ [from (a to $\mathrm{k}$ )] at $298 \mathrm{~K}$ temperature.

B. BSA fluorescence emission spectra in the presence of febuxostat, $\lambda_{\mathrm{ex}}=280 \mathrm{~nm}, \mathrm{CBSA}=2 \times 10^{-5} \mathrm{~mol} \mathrm{~L}^{-1}$; molar ratio of drug to protein is $0,1,2,3,4,5,7,9,11,14$, $16 \mu \mathrm{M}$ [from (a to $\mathrm{k})$ ] at $308 \mathrm{~K}$ temperature.

C. BSA fluorescence emission spectra in the presence of febuxostat, $\lambda_{\mathrm{ex}}=293 \mathrm{~nm}, \mathrm{CBSA}=2 \times 10^{-5} \mathrm{~mol} \mathrm{~L}^{-1}$; molar ratio of drug to protein is $0,1,2,3,4,5,7,9,11,14$, $16 \mu \mathrm{M}$ [from (a to $\mathrm{k})]$ at $298 \mathrm{~K}$ temperature.

D. BSA fluorescence emission spectra in the presence of febuxostat, $\lambda_{\mathrm{ex}}=293 \mathrm{~nm}, \mathrm{CBSA}=2 \times 10^{-5} \mathrm{~mol} \mathrm{~L}^{-1}$; molar ratio of drug to protein is $0,1,2,3,4,5,7,9,11,14$, $16 \mu \mathrm{M}$ [from (a to k)] at $308 \mathrm{~K}$ temperature, $\mathrm{pH}=7.40$. 
of the quencher (febuxostat), $\mathrm{K}_{\mathrm{q}}$ is the quenching rate constant of the bio-molecule, $K_{s v}$ is the Stern-Volmer quenching constant, and $\tau_{\mathrm{o}}(10$ $\left.{ }^{8} \mathrm{~s}\right)$ is the average lifetime of the fluorescent substance without any quencher [24].

At a greater concentration of quencher (Febuxostat), an emission spectrum was immerged in every spectral observation, taken at 280 and $293 \mathrm{~nm}$ in both temperatures respectively. The inherent emission bands of febuxostat were red shifted afterward the emission spectra of BSA, followed at around $380 \mathrm{~nm}$. These phenomena also detected throughout a fluorometric analysis with BSA-3-carboxyphenoxathiin (I) observation [26]. When the entire circulating protein complex is fully occupied with an examined ligand, the albumin-ligand complexes only works as a predominant species in the micro environment, take part in the fluoremetric emission process [27]. While in higher concentration of ligands, these further un-complexed ligands gather in the more hydrophobic region of the albumin and act as a predominated species, in raising the emission spectra toward at higher emission with the proportion of free ligands concentration availability [26,27].

This phenomenon of upward curvature also reported in many observations, done with many ligands and proteomics observation [2729]. Modified Stern-Volmer equation [27] can be applied to resolve such situation, where both static and dynamic quenching are operative, in view of exponential form of the model of the sphere of action, $\mathrm{V}$, equation (2) [30-32] or on the basis of quadratic dependence [33-35] upon quencher concentration model: from equation 2.

$$
\mathrm{F}_{0} / \mathrm{F}=\left\{1+\mathrm{K}_{\mathrm{sv}}{ }^{\star}[\mathrm{Q}]^{\star} \exp \left(\mathrm{V}^{\star}[\mathrm{Q}]\right)\right\}
$$

Where $\mathrm{F}_{0}, \mathrm{~F}$ is the fluorescence intensities of the albumin in the absence and presence of quencher [Q], $\mathrm{K}_{\mathrm{sv}}$ is Stern-Volmer quenching constant, Whereas, $\mathrm{V}$ is the volume of the sphere action. In Figure 3, the plot of modified Stern-Volmer equation is illustrated in both 280 and $293 \mathrm{~nm}$ excitation wavelength with the deviation occurred at two different temperatures at 298 and $308 \mathrm{~K}$, respectively. The constant values of $\mathrm{K}_{\mathrm{sv}}$ and $\mathrm{V}$ are included in Table 1.

Hence, equation (1) can be used to determine the value of $\mathrm{K}_{\mathrm{sv}}$ through a regression of the plot of $\mathrm{F}_{\mathrm{o}} / \mathrm{F}$ against $[\mathrm{Q}]$ and $\mathrm{K}_{\mathrm{q}}\left(\right.$ as $\mathrm{K}_{\mathrm{q}}=\mathrm{K}_{\mathrm{sv}}^{\mathrm{sv}} /$ $\tau_{\mathrm{o}}$ ). From the equation (2); the value of $\mathrm{K}_{\mathrm{sv}}$ and $\mathrm{V}$, the volume of the sphere of action can be calculated.

The concentration of quencher [Q] febuxostat, respectively; $\tau$ and $\tau$ imply the average lifetime of the bimolecular without and with the presence of quencher molecules. Figure 4; presented the SternVolmer plots at two different temperatures. The observation indicated that the Stern-Volmer plots are linear and the slopes increase with increase of temperature at $293 \mathrm{~nm}$, whereas opposite phenomena occur at $280 \mathrm{~nm}$ excitation wave length. The value for $\mathrm{K}_{\mathrm{sv}}, \mathrm{K}_{\mathrm{q}}$ and $\mathrm{R}^{2}$ at different temperatures are presented in Table 1. In case of modified Stern-Volmer equation, the quenching constant $\left(\mathrm{k}_{\mathrm{sv}}\right)$ increases in both excitation wavelength of 280 and $293 \mathrm{~nm}$. The volume of sphare action, $\mathrm{V}$ also increased upon incremental effect of temperatures.

As Stern-Volmer quenching constant $\left(\mathrm{K}_{\mathrm{sv}}\right)$ decrease with the increase in temperature for static quenching, while for the dynamic quenching reverse effect is observed [36]. The results showed that $\mathrm{K}_{\mathrm{sv}}$ was proportionally co-related with temperature increase at $293 \mathrm{~nm}$, which suggest that the fluorescence quenching process may be mainly controlled by a dynamic quenching mechanism rather than a static quenching mechanism. Additionally, an inversely relationship of $\mathrm{K}_{\mathrm{sv}}$ with temperature also reported at an excitation wavelength of $280 \mathrm{~nm}$. A Static quenching mechanism observed at the excitation wavelength of $280 \mathrm{~nm}$. In case of modified Stern-Volmer plot, a shape indication for dynamic quenching was noted, within the experimental drug/ protein $(\mathrm{d} / \mathrm{p}=0-16)$ ratio.
A

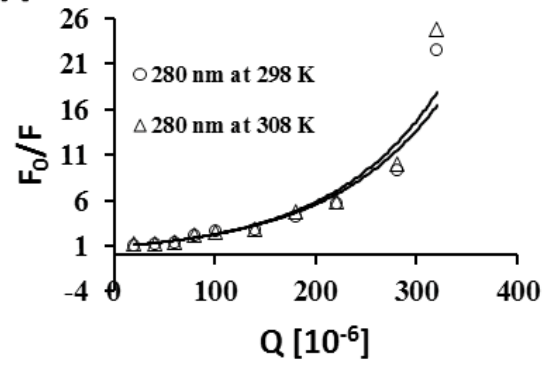

B

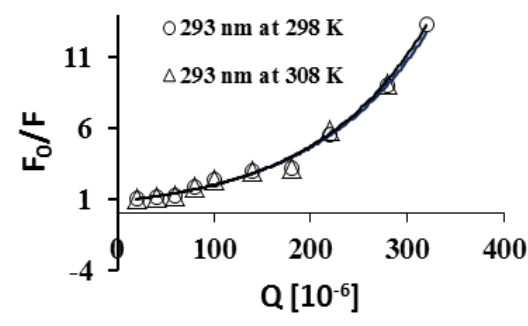

Figure 3: A. Modified Stern-Volmer plots of Febuxostat-BSA system (at d/p ratio: $0-16)$ in $\lambda_{\mathrm{ex}}=280 \mathrm{~nm} ; \lambda_{\mathrm{em}}=380 \mathrm{~nm}$ at $\mathrm{pH}=7.40$ at different temperatures: (O) $298 \mathrm{~K}$ $(\Delta) 308 \mathrm{~K}$. B. Modified Stern-Volmer plots of Febuxostat-BSA system in $\lambda_{\mathrm{ex}}=293 \mathrm{~nm} ; \lambda_{\mathrm{em}}=380 \mathrm{~nm}$ at $\mathrm{pH}=7.40$ at different temperatures: $(\mathrm{O}) 298 \mathrm{~K},(\Delta) 308 \mathrm{~K}$

\begin{tabular}{|c|c|c|c|c|c|c|c|c|}
\hline \multirow[b]{2}{*}{$\lambda_{\mathrm{ex}}$} & \multirow[b]{2}{*}{$\mathrm{pH}$} & \multirow[b]{2}{*}{$\mathrm{T}(\mathrm{K})$} & \multicolumn{3}{|c|}{ Equation (01) } & \multicolumn{3}{|c|}{ Equation (02) } \\
\hline & & & $\begin{array}{c}\mathrm{K}_{\mathrm{sv}} \\
\left(\times 10^{4} \mathrm{~L}^{\mathrm{mol}} \mathrm{mol}^{-1}\right)\end{array}$ & $\left(\times 10^{12} \stackrel{K_{q}}{\text { L.mol }}\right.$ mol $\left.^{-1} \cdot \mathrm{s}^{-1}\right)$ & $\mathbf{R}^{2(a)}$ & $\begin{array}{c}\mathrm{K}_{\mathrm{sv}} \\
\left(\times 10^{4} \mathrm{~L}^{\mathrm{mol}}{ }^{-1}\right)\end{array}$ & $\begin{array}{c}V \times 10^{4} \\
\left(M^{-1}\right)\end{array}$ & $\mathbf{R}^{2(\mathrm{a})}$ \\
\hline \multirow{2}{*}{$280 \mathrm{~nm}$} & \multirow{2}{*}{7.40} & 298 & $13.7 \pm 0.017$ & $13.7 \pm 0.017$ & 0.9636 & $7.91 \pm 0.10$ & $0.90 \pm 0.13$ & 0.9691 \\
\hline & & 308 & $12.5 \pm 0.029$ & $12.5 \pm 0.029$ & 0.9762 & $9.68 \pm 0.21$ & $0.93 \pm 0.17$ & 0.9713 \\
\hline \multirow{2}{*}{$293 \mathrm{~nm}$} & \multirow{2}{*}{7.40} & 298 & $17.2 \pm 0.005$ & $17.2 \pm 0.05$ & 0.9682 & $13.40 \pm 0.07$ & $0.84 \pm 0.08$ & 0.9865 \\
\hline & & 308 & $18.5 \pm 0.006$ & $18.5 \pm 0.006$ & 0.9782 & $14.56 \pm 0.09$ & $0.86 \pm 0.12$ & 0.9857 \\
\hline
\end{tabular}

${ }^{\text {a) }} R^{2}$ is the correlation co-efficient.

Table 1: Stern-Volmer quenching constants, to eq. (1) and modified Stern-Volmer quenching constant, to eq. (2); of BSA-Febuxostat system at different temperatures $(\mathrm{pH}=7.40)$. 


\section{Analysis of binding parameter}

The equilibrium between free and bound molecules due to the binding of a micro molecule into a site of macromolecules can be given by the equation [36]: from equation 3 .

$$
\log \frac{F_{0}-F}{F}=\log K_{b}+n \log [Q]
$$

Where, $K_{b}$ and $n$ are the binding constant and the number of binding sites, respectively. Table 2 ; shows that the values of $\mathrm{K}_{\mathrm{b}}$ increased with increase of temperature at $280 \mathrm{~nm}$ excitation wavelength, which may indicate that there was a molecular binding of febuxostat with BSA forming a stable complex with a molar ratio of about $\sim 1.5: 1$ in between febuxostat and BSA molecules. It can be implicated that febuxostat indicated a higher affinity to BSA, with the binding of 1.5 moles of febuxostat with 1 mole of BSA. The complex begins to decompose when the temperature increases in case of excitation wavelength of 293 nm (Figure 5).

\section{Thermodynamic parameters and the behavior of pattern forces}

Hydrogen bond, van der Waals force, hydrophobic interaction, including electrostatic is the most common form of force govern in the binding between a small molecule (agonist) and a macromolecule (Protein). The thermodynamic parameters were determined using the Van't Hoff equation [37]: from equation 4.

$$
\operatorname{InKb}=-\left(\Delta \mathrm{H}_{\mathrm{o}} / \mathrm{RT}\right)+\left(\Delta \mathrm{S}_{\mathrm{o}} / \mathrm{R}\right)
$$

Where, $\Delta \mathrm{S}_{\mathrm{o}}=$ Entropy change, $\Delta \mathrm{H}_{\mathrm{o}}=$ Enthalpy change, $\mathrm{R}=$ Universal gas constant and $\mathrm{K}_{\mathrm{b}}=$ Analogous to the Stern-Volmer quenching constants $\mathrm{K}_{\mathrm{sv}}$ at the corresponding temperature [24].

In equation (4), $\mathrm{K}_{\mathrm{b}}$ corresponds to the modified Stern-Volmer association constant at specific temperatures and $\mathrm{R}$ is the gas constant. The plot of Ink vs $1 / T$ originates for determining of the values of $\Delta \mathrm{H}_{\mathrm{o}}$ and $\Delta \mathrm{S}_{\mathrm{o}}$ (Figure 6). The free energy change $\Delta \mathrm{G}_{\mathrm{o}}$ of the binding reaction at different temperature was estimated from the relation (5): from equation 5 .

$$
\Delta \mathrm{G}_{\mathrm{o}}=\Delta \mathrm{H}_{\mathrm{o}}-\mathrm{T} \Delta \mathrm{S}_{\mathrm{o}}
$$

Value of $\Delta \mathrm{G}_{\mathrm{o}}, \Delta \mathrm{H}_{\mathrm{o}}$ and $\Delta \mathrm{S}_{\mathrm{o}}$ are listed in Table 2.

A positive value of $\Delta \mathrm{S}$ was evidence for hydrophobic interaction; the negative $\Delta \mathrm{H}_{\mathrm{o}}$ values ensured the existence of hydrogen bonding
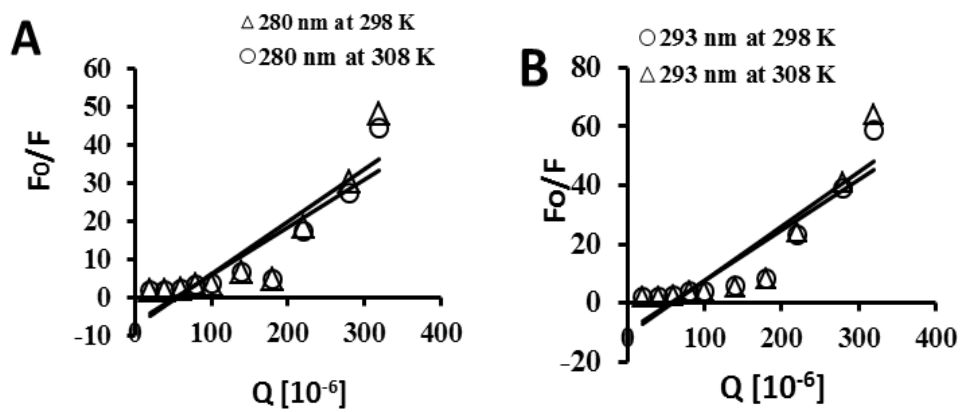

\begin{tabular}{|c|c|c|c|c|c|c|c|}
\hline$\lambda_{\mathrm{ex}}$ & $\mathrm{T}(\mathrm{K})$ & $\operatorname{lnK}_{\mathrm{sv}}$ & $\mathrm{K}_{\mathrm{b}}\left(\times 10^{3} \mathrm{~L} \mathrm{~mol}^{-1}\right)$ & $\mathrm{n}$ & $\Delta \mathrm{G}_{\mathrm{o}}\left(\mathrm{kJ} \mathrm{mol}^{-1}\right)$ & $\Delta \mathrm{H}_{\mathrm{o}}\left(\mathrm{kJ} \mathrm{mol}^{-1}\right)$ & $\Delta \mathrm{S}_{0}\left(\mathrm{~J} \mathrm{~mol}^{-1} \mathrm{~K}^{-1}\right)$ \\
\hline \multirow[t]{2}{*}{$280 \mathrm{~nm}$} & 298 & 11.827 & 3.467 & 1.522 & -29.309 & \multirow[t]{2}{*}{-6.9987} & \multirow[t]{2}{*}{74.868948} \\
\hline & 308 & 11.736 & 4.943 & 1.45 & -30.053 & & \\
\hline \multirow[b]{2}{*}{$293 \mathrm{~nm}$} & 298 & 12.055 & 5.54 & 1.481 & -29.86 & \multirow[t]{2}{*}{5.57172} & \multirow[t]{2}{*}{118.9188} \\
\hline & 308 & 12.128 & 4.436 & 1.527 & -31.05 & & \\
\hline
\end{tabular}

Figure 4: A. The Stern-Volmer plots of BSA quenched by febuxostat in $\lambda=280 \mathrm{~nm}$ at different temperatures: (O) $298 \mathrm{~K},(\Delta) 308 \mathrm{~K}$. B. The Stern-Volmer plots of BSA quenched by febuxostat in $\lambda_{\mathrm{ex}}=293 \mathrm{~nm}$ at $\mathrm{pH}=7.40$ at different temperatures: $(\mathrm{O}) 298 \mathrm{~K},(\Delta) 308 \mathrm{~K}$.

Table 2: Modified Stern-Volmer association constants $K_{b}$, number of binding sites, $n$ and thermodynamic parameters of the interaction of febuxostat with BSA at different temperature $(\mathrm{pH}=7.40)$.
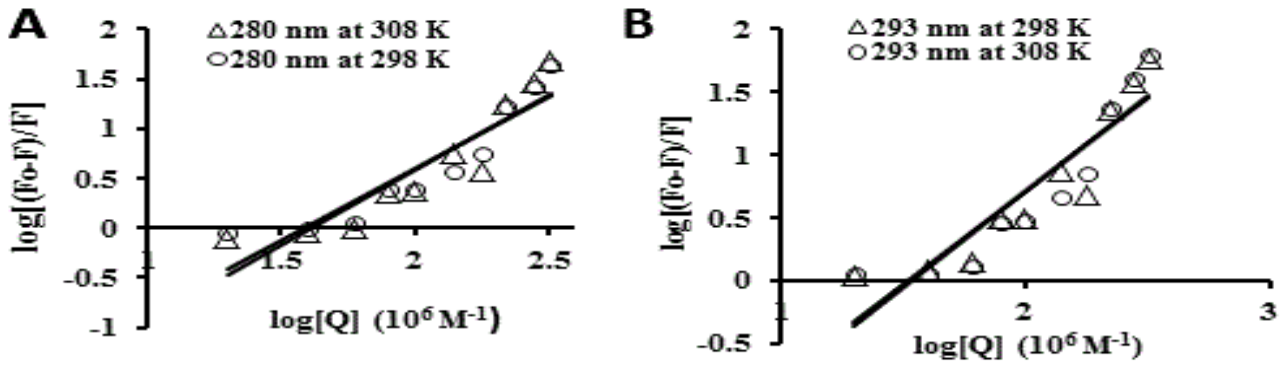

Figure 5: A. Logarithmic plot of the fluorescence quenching of BSA at various concentrations of febuxostat in excited wavelength $(\lambda) 280 \mathrm{~nm}$ at $298 \mathrm{~K}(\mathrm{O})$ and $308 \mathrm{~K}(\Delta)$. B. Logarithmic plot of the fluorescence quenching of BSA at various concentrations of febuxostat in excited wavelength $\left(\lambda_{\mathrm{ex}}\right) 293 \mathrm{~nm}$ at $298 \mathrm{~K}(\mathrm{O})$ and $308 \mathrm{~K}(\Delta)$. 

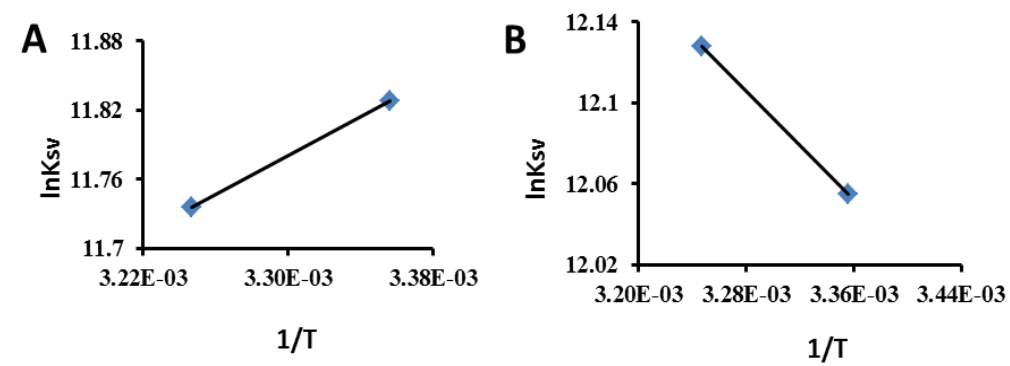

Figure 6: A. Van't Hoff plot showing the interaction of febuxostat with BSA at pH 7.40 in $\lambda_{\mathrm{ex}}=280 \mathrm{~nm}$. B. Van't Hoff plot showing the interaction of febuxostat with BSA at $\mathrm{pH} 7.40$ in $\lambda_{\mathrm{ex}}=293 \mathrm{~nm}$.

in the binding process [37,38]. Furthermore, the main source of $\Delta \mathrm{G}_{\mathrm{o}}$ value was derived from a large contribution of the $\Delta \mathrm{S}_{\mathrm{o}}$ terms with a small contribution from the $\Delta \mathrm{H}_{\mathrm{o}}$, so the main interaction was hydrophobic and a small fraction of hydrogen bonding in nature due to negative $\Delta \mathrm{H}_{\mathrm{o}}$, observed in the excitation wavelength of $280 \mathrm{~nm}$. Only hydrophobic interaction was recorded at an excitation wavelength of $293 \mathrm{~nm}$. Negative (Energy change) $\Delta \mathrm{G}_{\mathrm{o}}$ postulate the spontaneous binding process throughout the interactions [37].

Binding constant $\mathrm{K}_{\mathrm{b}}$, increase with the increase of temperature at $280 \mathrm{~nm}$ excitation wavelength, ensured the stability of the BSAFebuxostat complex along with temperature increment. Moreover, an inversely proportional association was observed at an excitation wavelength of $293 \mathrm{~nm}$ whereas the stability of complex decreases with the increase in temperature. Number of assumed binding site $n$; was more than 1, which indicated the higher affinity of febuxostat with the BSA protein.

\section{Conclusion}

The fluorescence spectroscopic method was applied to study the interactions and the nature of binding with febuxostat and BSA in a temperature differential process. The experimental results indicated that quenching of the fluorescence of BSA by febuxostat was probably followed a static as well as dynamic mechanism and the binding reaction was mainly enthalpy driven, where hydrophobic interaction played a major role. The binding nature assumed that the maximum binding occurs in the principal regions of ligand binding domain, located in hydrophobic cavities in the sub domains IIA and IIIA $[5,6]$. A phenomenon of mixed static and dynamic quenching was observed at both 280 and $293 \mathrm{~nm}$ excitation wavelength $\left(\lambda_{\mathrm{ex}}\right)$, whereas emission occurred at $\lambda_{\mathrm{em}}=380 \mathrm{~nm}$, which is careful illustrated with modified Stern-Volmer equation. Binding constant $\mathrm{K}_{\mathrm{b}}$, suggested that the stability of binding increases with the increase of temperature in most cases. Increase of stability of the complex observed at $280 \mathrm{~nm}$ whereas the reverse effect was observed at $293 \mathrm{~nm}$ with increase of temperature. The Molar ratio of BSA-Febuxostat indicated that, 1 mole of BSA binds with $\sim 1.5$ moles of febuxostat. Pharmacokinetics view point suggested that, drug with higher affinity with plasma protein normally has a low therapeutic index, indicating high risk of toxicity due to a slide alteration in dosing [18]. Being an anti-gout drug febuxostat, need to take as prolong therapy to improve on patient's disease state with effective management of blood uric acid level. So, a study like this can be helpful in safe dosing regimen towards a better therapeutic outcome and toxicity minimization comparing with human serum albumin.

\section{Acknowledgment}

Authors would like to thank Incepta pharmaceutical Ltd., Bangladesh for supporting this study by proving drugs.

\section{References}

1. Lázaro E, Lowe PJ, Briand X, Faller B (2008) New approach to measure protein binding based on a parallel artificial membrane assay and human serum albumin. J Med Chem 51: 2009-2017.

2. Flarakos J, Morand KL, Vouros P (2005) High-throughput solution-based medicinal library screening against human serum albumin. Anal Chem 77 1345-1353.

3. Mallick A, Bera SC, Maiti S, Chattopadhyay N (2004) Fluorometric investigation of interaction of 3-acetyl-4-oxo-6,7-dihydro-12H indolo-[2,3-a] quinolizine with bovine serum albumin. Biophys Chem 112: 9-14.

4. Sun SF, Zhou B, Hou HN, Liu Y, Xiang GY (2006) Studies on the interaction between Oxaprozin-E and bovine serum albumin by spectroscopic methods. Int J Biol Macromol 39: 197-200.

5. Kandagal PB, Ashoka S, Seetharamappa J, Shaikh SM, Jadegoud Y, et al. (2006) Study of the interaction of an anticancer drug with human and bovine serum albumin: Spectroscopic approach. J Pharm Biomed Anal 41: 393-399.

6. Sato T, Saito Y, Chikuma M, Saito Y, Nagai S (2008) Determination of albumin in bronchoalveolar lavage fluid by flow-injection fluorometry using chromazuro S. Biol Pharm Bull 31: 336-339.

7. Hu YJ, Liu Y, Fang XY, Qu SS (2005) Studies on the interaction between 1-hexylcarbamoyl-5-fluorouracil and bovine serum albumin. Molecular Structure 738: 143-147.

8. Pedersen AO, Mensberg KL, Kragh-Hansen U (1995) Effects of ionic strength and $\mathrm{pH}$ on the binding of medium-chain fatty acids to human serum albumin Eur J Biochem 233: 395-405

9. He XM, Carter DC (1992) Atomic structure and chemistry of human serum albumin. Nature 358: 209-215.

10. Carter DC, Ho JX (1994) Structure of serum albumin. Adv Protein Chem 45 153-203.

11. Carter DC, Chang B, Ho JX, Keeling K, Krishnasami Z (1994) Preliminary crystallographic studies of four crystal forms of serum albumin. Eur J Biochem 226: 1049-1052.

12. Schlesinger N (2004) Management of acute and chronic gouty arthritis: Present state-of-the-art. Drugs 64: 2399-2416.

13. Terkeltaub RA (2003) Clinical practice. Gout. N Engl J Med 349: 1647-1655

14. Hu M, Tomlinson B (2008) Febuxostat in the management of hyperuricemia and chronic gout: A review. Ther Clin Risk Manag 4: 1209-1220.

15. Jordan KM, Cameron JS, Snaith M, Zhang W, Doherty M, et al. (2007) British Society for Rheumatology and British Health Professionals in Rheumatology guideline for the management of gout. Rheumatology (Oxford) 46: 1372-1374.

16. Becker MA, Chohan S (2008) We can make gout management more successful now. Curr Opin Rheumatol 20: 167-172. 
Citation: Rabbi SNI, Sultan MdZ, Sohel MdD, Sultan MdZ (2015) Study of Interaction between Febuxostat and Bovine Serum Albumin by Fluorescence Spectroscopy. J Bioanal Biomed 7: 164-170. doi:10.4172/1948-593X.1000138

17. Shoji A, Yamanaka $\mathrm{H}$, Kamatani N (2004) A retrospective study of the relationship between serum urate level and recurrent attacks of gouty arthritis: Evidence for reduction of recurrent gouty arthritis with antihyperuricemic therapy. Arthritis Rheum 51: 321-325.

18. Dalbeth N, Kumar S, Stamp L, Gow P (2006) Dose adjustment of allopurino according to creatinine clearance does not provide adequate control of hyperuricemia in patients with gout. J Rheumatol 33: 1646-1650.

19. Takeda Pharmaceuticals North America (2011) Uloric Full Prescribing Information.

20. Becker MA, Schumacher HR Jr, Wortmann RL, MacDonald PA, Eustace D, et al. (2005) Febuxostat compared with allopurinol in patients with hyperuricemia and gout. N Engl J Med 353: 2450-2461.

21. Schumacher HR Jr, Becker MA, Wortmann RL, Macdonald PA, Hunt B, et al. (2008) Effects of febuxostat versus allopurinol and placebo in reducing serum urate in subjects with hyperuricemia and gout: A 28-week, phase III, randomized, double-blind, parallel-group trial. Arthritis Rheum 59: 1540-1548.

22. Becker MA, Schumacher HR, Espinoza LR, Wells AF, MacDonald $P$, et al. (2010) The urate-lowering efficacy and safety of febuxostat in the treatment of the hyperuricemia of gout: The CONFIRMS trial. Arthritis Res Ther 12: R63.

23. Silva D, Cortez CM, Cunha-Bastos J, Louro SR (2004) Methyl parathion interaction with human and bovine serum albumin. Toxicol Lett 147: 53-61.

24. Lakowicz JR, Weber G (1973) Quenching of fluorescence by oxygen. A probe for structural fluctuations in macromolecules. Biochemistry 12: 4161-4170.

25. Kandagal PB, Shaikh SMT, Manjunatha DH, Seetharamappa J, Nagarall BS (2007) Spectroscopic studies on the binding of bioactive phenothiazine compounds to human serum albumin. J Photochem Photobiol A 189: 121-127.

26. Oana V, Tintaru V, Gavriliu V, Maior V, Hillebrand M (2002) Experimenta and Theoretical Study of the Inclusion Complexes of Some Phenoxathiin Derivatives with B -Cyclodextrin. J Phys Chem 106: 257-263.

27. Varlan A, Hillebrand M (2010) Bovine and Human Serum Albumin Interactions with 3-Carboxyphenoxathiin Studied by Fluorescence and Circular Dichroism Spectroscopy. Molecules 15: 3905-3919.

28. Eftink MR, Ghiron CA (1981) Fluorescence quenching studies with proteins Anal Biochem 114: 199-227.

29. Wang YQ, Zhang HM, Zhang GC, Tao WH, Fei ZH, et al. (2007) Spectroscopic studies on the interaction between silicotungstic acid and bovine serum albumin. J Pharm Biomed Anal 43: 1869-1875.

30. Thipperudrappa J, Biradar DS, Lagare MT, Hanagodimath SM, Inamdar SR, et al. (2006) Fluorescence quenching of BPBD by aniline in benzene-acetonitrile mixtures. Journal of Photochemistry and Photobiology A: Chemistry 177: 89-93.

31. Wang N, Ye L, Yan F, Xu R (2008) Spectroscopic studies on the interaction of azelnidipine with bovine serum albumin. Int J Pharm 351: 55-60.

32. Kamat BP, Seetharamappa J (2004) In vitro study on the interaction of mechanism of tricyclic compounds with bovine serum albumin. J Pharm Biomed Anal 35: 655-664.

33. Shaikh SMT, Seetharamappa J, Kandagal PB, Manjunatha DH, Ashoka $S$ (2007) Spectroscopic investigations on the mechanism of interaction of bioactive dye with bovine serum albumin. Dyes Pigm 74: 665-671.

34. Melavanki RM, Kusanur RA, Kadadevaramath JS, Kulakarni MV (2009) Quenching mechanisms of 5BAMC by aniline in different solvents using SternVolmer plots. J Lumin 129: 1298-1303.

35. Wang YQ, Zhang HM, Zhang GC, Tao WH, Tang SH (2007) Binding of brucine to human serum albumin. J Mol Struct 830: 40-45.

36. Ross PD, Subramanian S (1981) Thermodynamics of protein association reactions: Forces contributing to stability. Biochemistry 20: 3096-3102.

37. Mallick A, Haldar B, Chattopadhyay N (2005) Spectroscopic investigation on the interaction of ICT probe 3-acetyl-4-oxo-6,7-dihydro-12H Indolo-[2,3-a] quinolizine with serum albumins. J Phys Chem B 109: 14683-14690.

38. Tian J, Liu J, Hu Z, Chen X (2005) Interaction of wogonin with bovine serum albumin. Bioorg Med Chem 13: 4124-4129. 